\title{
Mechanisms of Anti-Melanogenic and Proliferative Effects of Colla Corii Asini (E'jiao)
}

\author{
Chien Wei Hou* \\ Professor, Department of Biotechnology and Pharmaceutical Technology, Yuanpei University of Medical Technology, ROC
}

${ }^{\star}$ Corresponding author: Chien Wei Hou, Professor, Department of Biotechnology and Pharmaceutical Technology, Yuanpei University of Medical Technology, ROC; Fax: +886-3-6102312; E-mail: rolis.hou@mail.ypu.edu.tw

Received: March 29, 2021; Accepted: April 05, 2021; Published: April 07, 2021

\begin{abstract}
Natural compounds have been reported for the development of cosmetic skin care products but it remains a challenge to find safe and useful ones. Colla corii asini (E'jiao), or donkey-hide gelatin (DHG) prepared by concentrating stewed Equus asinus L. donkey hide, has been useful in traditional Chinese medicine. However, its anti-melanogenic and skin care effects have not been explored. In this study, the biological effect of DHG was tested on murine B16-F10 melanocytes and human HaCaT keratinocytes. The cell signal pathway mechanisms by DHG were also examined by western blot assay. The results showed that DHG was not cytotoxic to cells and had an anti-melanogenic effect by inhibiting tyrosinase activity and reducing melanin contents in B16-F10 melanocytes. It also showed an anti-oxidative effect of reducing ROS generation in $\mathrm{H}_{2} \mathrm{O}_{2}$-stressed HaCaT keratinocytes. DHG dose-dependently enhanced phosphorylation of ERK, but reduced p-JNK and p-p38 proteins in B16-F10 cells under the UV stress. This is consistent with the results of other anti-melanogenic agents. Therefore, this suggested DHG had a potential for skin whitening and skin care applications.
\end{abstract}

Keywords: Anti-melanogenesis, Donkey-hide gelatin, E'jiao, Proliferation, UV stress

\section{Introduction}

Medicinal products have been used for centuries to promote healthy skin. Skin care products have gained a competitive market not only for clinical applications but also for esthetical purpose. Despite the widespread use of natural ingredients, the discovery of biologically active compounds, the development of these substances into new cosmetic products remain an important challenge [1]. Skin pigmentation is caused by melanins, which are synthesized by melanocytes [2]. Tyrosinase is an enzyme that catalyzes two rate-limiting reactions in melanogenesis including hydroxylation of L-tyrosine into L-3,4-dihydroxyphenylalanine (L-DOPA) and further oxidation of L-DOPA into dopaquinone, while highly reactive dopaquinone can spontaneously polymerize to form melanin [3]. Many tyrosinase inhibitors from natural or synthetic sources have been reported to include polyphenols, benzaldehyde and benzoate derivatives, long-chain lipids and steroids, other natural or synthetic inhibitors, and irreversible inhibitors [4]. However, few tyrosinase inhibitors are applied in cosmetic and medicinal fields for skinlightening due to their toxicity or potential hazards [5]. Therefore it is necessary to search a natural anti-melanogenic agent without significant side effects.

Colla corii asini (E'jiao), donkey-hide gelatin (DHG) prepared by concentrating stewed Equus asinus L. donkey hide, is a traditional Chinese medicinal ingredient. It has been used in China for antianemic therapy for over 2,000 years [6,7]. The chemical constituents of Colla corii asini include amino acids, proteins/gelatins, polysaccharides, volatile substances, and inorganic substances. It has been reported as having anti-aging, antitumor, immunomodulatory, anti-inflammatory effects $[8,9]$. However, its potential for skin care or skin whitening has not been explored.

In this study, the antimelanogenic effect of DHG was evaluated in murine B16-F10 melanoma cells and the antioxidative effect in human $\mathrm{HaCaT}$ keratinocytes. Because the extracellular signal-regulated kinase (ERK) and phosphatidylinositol 3-kinase (PI3K)/Akt signaling pathways have been shown to negatively regulate melanogenesis in melanocytes and melanoma cells $[10,11]$, we also investigated the effect of DHG on these signaling pathways. The beneficial mechanisms of DHG on these cells were examined for its potential application on the skin care.

\section{Materials and Methods}

\section{Chemicals}

Donkey hide gelatin (Colla corii asini, DHG or e-jiao) was purchased from Dong-E-E-Jiao Co., Ltd. (Dong'E, Shangdon, China). Mushroom tyrosinase (3320 units/mg), 3,4-dihydroxy-L-phenylalanin (L-dopa), sodium hydroxide $(\mathrm{NaOH})$ and other reagents were obtained from Sigma-Aldrich (St. Louis, MO, USA). Murine melanoma cellline, B16-F10 (BCRC60031) and human keratinocytes HaCaT cellline were gifts of Dr. Chih-Cheng Lin and originally obtained from the Bioresource Collection and Research Center (BCRC, Hsinchu, Taiwan). Fetal bovine serum (FBS), penicillin/streptomycin (P/S), and Dulbecco's modified Eagle's medium (DMEM) were purchased form Hyclone (Logan, UT, USA). A TD-3D skin analyzer with whole spectrum, cross-polarized, and UV lighting was used to record and 
measure surface and subsurface skin conditions. The analyzer was obtained from Hofonchu Corp (New Taipei, Taiwan).

\section{Cell Culture and Viability Assay}

The B16-F10 cells and HaCaT keratinocytes were cultured in DMEM medium with $10 \% \mathrm{FBS}, 50 \mathrm{mg} / \mathrm{ml} \mathrm{P} / \mathrm{S}$ at $37^{\circ} \mathrm{C}$ with a $5 \% \mathrm{CO}$ incubator. The B16-F10 cells or HaCaT cells were seeded in 24-well plates at a density of $5 \times 10^{5}$ cells/well. DHG extract was prepared with either double distilled (RO) water or ethanol ( $1 \mathrm{~g} / 10 \mathrm{ml})$. After 24 $\mathrm{h}$ of incubation, the culture medium was replaced with fresh culture medium containing various concentrations of DHG and further incubated for another $24 \mathrm{~h}$. The cell viability was determined by using the 3-(4,5-dimethylthiazol-2-yl)-2,5-diphenyltetrazolium bromide (MTT) method. The culture was washed with phosphate buffered saline (PBS) and replaced with MTT solution, and then incubated at $37^{\circ} \mathrm{C}$ for $1 \mathrm{~h}$. The formazan formed by dimethyl sulfoxide (DMSO) solubilized cells was determined at an absorbance of $540 \mathrm{~nm}$ using an ELISA reader (Molecular Devices, Sunnyvale, CA, USA).

\section{Skin Analysis}

DHG was grinded with normal saline $(1 \mathrm{~g} / 9 \mathrm{ml})$ for $5 \mathrm{~min}$ and centrifuged at $3000 \mathrm{~g}$ for $10 \mathrm{~min}$. One $\mathrm{ml}$ of the supernatant was added to the filter paper $\left(9 \times 9 \mathrm{~cm}^{2}\right)$. The filters containing either DHG or RO water were then laid on a volunteer's left and right cheek, respectively, for 15 min. After rinsing with RO water, gently dry cheek with lens paper, waiting for $5 \mathrm{~min}$, and the volunteer's facial skin was assessed with a TD-3D skin analyzer. Stain, wrinkles, and skin texture were analyzed for the effects of DHG. Since tyrosinase is a significant key in melanogenesis, tyrosinase inhibition is a common method to avoid melanin biosynthesis. The effect of DHG on tyrosinase activity of B16-F10 cells was determined [12]. The cells were seeded at $1 \sim 3 \times 10^{5}$ with $10 \mathrm{ml}$ DMEM complete medium (10\% FBS, $50 \mathrm{mg} / \mathrm{ml} \mathrm{P} / \mathrm{S}$ ) in 24 well plates and treated with various concentrations of DHG for $48 \mathrm{~h}$. The cells were then harvested by using a lysis buffer (0.1 M PBS, pH 6.8, containing $1 \%$ Triton X-100 and protease inhibitor). Cells were then disrupted by repeatedly freezing and thawing five times. Cell lysates were centrifuged at $14,000 \mathrm{~g}$ for $15 \mathrm{~min}$. The protein concentration in the supernatant from cell lysate was determined by using Bradford assay (Bio-Rad, Richmond, CA, USA) and normalized. After preheated to $37^{\circ} \mathrm{C}$, an aliquot of $50 \mu \mathrm{l}$ of each samples was transferred into a well of the 96-well plate and reacted with $50 \mu \mathrm{lof} 1 \mathrm{mg} / \mathrm{ml}$ L-DOPA at $37^{\circ} \mathrm{C}$ for $1 \mathrm{~h}$. Tyrosinase activity was then determined by measurement of the absorbance at $475 \mathrm{~nm}$ dynamically within 30 $\mathrm{min}$. The molar absorbance coefficient $3700(\mathrm{~mol} / \mathrm{l} \cdot \mathrm{cm})-1$ was used to calculate tyrosinase activity. Tyrosinase activity unit was defined as the amount of enzyme required to oxidize $1 \mu \mathrm{M}$ min-1 of the substrate (L-DOPA) under standard assay conditions. The inhibition rate of tyrosinase activity $(\%)=(\mathrm{A}-\mathrm{B}) / \mathrm{A} \times 100 \%$.

A: Absorbance of the non-treated sample, B: Absorbance of the DHG-treated sample

\section{Measurement of Melanin Content}

B16-F10 cells were seeded at a density of $5 \times 105$ cells $/ \mathrm{ml}$ in the 24-well culture plates and incubated at $37^{\circ} \mathrm{C}$ with $5 \% \mathrm{CO}_{2}$ for $24 \mathrm{~h}$. The
B16-F10 cells were treated with various concentrations of DHG for $24 \mathrm{~h}$ under $100 \mathrm{~mJ}$ of UV exposure. After washed with PBS, the culture was centrifuged for $30 \mathrm{~min}$ at $12000 \mathrm{~g}$, and treated with $100 \mu \mathrm{l}$ of $1 \mathrm{~N} \mathrm{NaOH}$ solution for $30 \mathrm{~min}$ at $60^{\circ} \mathrm{C}$. For the melanin content, an aliquot of $80 \mu \mathrm{l}$ of culture medium was transferred to a microplate and determined at an absorbance of $405 \mathrm{~nm}$ with a melanin standard curve [13].

\section{Measurement of Reactive Oxygen Species (ROS)}

ROS was determined with $\mathrm{H}_{2}$ DCF-DA [10]. This nonfluorescent compound accumulates within cells upon deacetylation. $\mathrm{H}_{2} \mathrm{DCF}$ then reacts with ROS to form fluorescent dichlorofluorescein (DCF). HaCaT cells were plated in 96-well plates and grown for 24 $\mathrm{h}$ before the addition of DMEM plus $10 \mu \mathrm{M} \mathrm{H_{2 } D C F - D A}$ and various concentrations of DHG, incubation for $1 \mathrm{~h}$ at $37^{\circ} \mathrm{C}$, and treatment with $800 \mu \mathrm{M} \mathrm{H}_{2} \mathrm{O}_{2}$ for 60 or $120 \mathrm{~min}$. Cells were then washed twice with room temperature Hank's balanced salt solution (HBSS without phenol red). Cellular fluorescence was monitored on a Fluoroskan Ascent fluorometer (Labsystems Oy, Helsinki, Finland) using an excitation wavelength of $485 \mathrm{~nm}$ and emission wavelength of $538 \mathrm{~nm}$. The inhibition of ROS was calculated as the previous formula.

\section{Western Blot Assay}

B16-F10 cells and HaCaT cells were plated in 24-well plates and grown for $24 \mathrm{~h}$. Then both types of cells were incubated with various concentration of DHG for $1 \mathrm{~h}$ at $37^{\circ} \mathrm{C}$, but only B16-F10 cells were under UV $(100 \mathrm{~mJ})$ stress. Extracted protein samples from each treatment group (containing $50 \mu \mathrm{g}$ of protein) were separated on $12 \%$ sodium dodecyl sulfate-polyacrylamide gels and transferred to immobile polyvinylidene difluoride membranes (Millipore, Billerica, MA). The membranes were incubated for $1 \mathrm{~h}$ with $5 \%$ dry skim milk in TBST buffer (0.1M Tris- $\mathrm{HCl}, \mathrm{pH} 7.4,0.9 \% \mathrm{NaCl}, 0.1 \%$ Tween-20) to block non-specific binding. Then, they were incubated with rabbit antibodies against AKT, p-JNK, p-ERK, p-p38 (Abcam, Cambridge, UK), and anti- $\beta$-actin (Jackson, West Grove, PA, USA). Subsequently, the membranes were incubated with the conjugated affinity goat antirabbit IgG (Jackson). Expression of these proteins was detected by a chemiluminescence detection system according to the manufacturer's instructions (ECL, Amersham, Berkshire, UK) [10].

\section{Results}

\section{Effect of DHG on Cell Viability}

The effect of DHG on cell viability of human keratinocyte $\mathrm{HaCaT}$ cells and murine B16-F10 cells was evaluated. Cells treated with various concentrations were examined for cell viability by MTT assay. As shown in Figure 1, DHG from water extract did not exhibit a cytotoxic effect. Instead, it demonstrated a proliferative effect on $\mathrm{HaCaT}$ cells at concentrations of $0.5 \sim 1.0 \mathrm{mg} / \mathrm{ml}$. Likewise, DHG at these ranges did not exhibit a cytotoxic effect on B16-F10 cells.

\section{Effect of DHG on Skin Test}

A brief treatment of DHG showed a skin care effect. Skin analysis showed that the facial skin texture, pores, wrinkles, and red spots were significantly improved in ten healthy volunteers after DHG treatment (Table 1). 
(A)

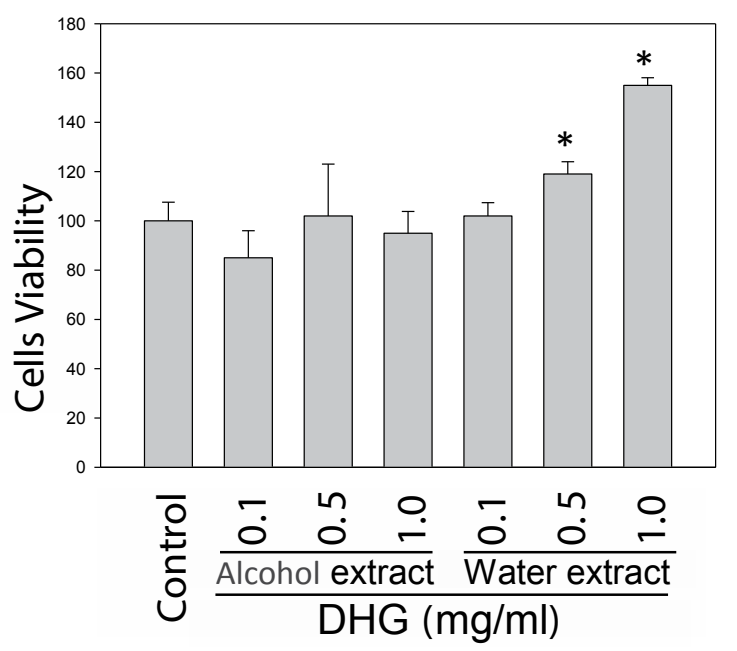

(B)

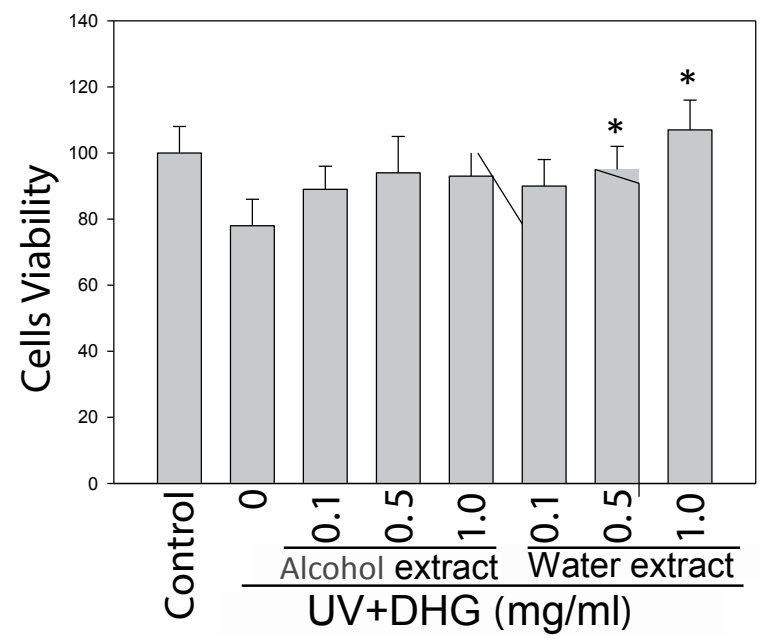

Figure 1: Effect of DHG on the cell viability by MTT assay. Human keratinocyte HaCaT cells or murine B16-F10 melanocytes were treated with various concentrations of DHG for $24 \mathrm{~h}$ and examined for cell viability. Each value is the mean \pm SE from three experiments. ${ }^{*} p<$ 0.05 as compared with the HaCaT control (A), or UVB-treated control of B16-F10 cells (B).

Table 1: Effect of DHG treatment on facial skin analysis.

\begin{tabular}{|c|c|c|}
\hline Items & Control (Water) & DHG $(\mathbf{0 . 1} \mathbf{g} / \mathbf{m l})$ \\
\hline Texture & $37 \pm 5$ & $26 \pm 3^{*}$ \\
\hline Pore & $25 \pm 4$ & $17 \pm 3^{*}$ \\
\hline Wrinkles & $14 \pm 3$ & $8 \pm 3^{*}$ \\
\hline Erythema & $40 \pm 7$ & $25 \pm 7^{*}$ \\
\hline Glossy & $48 \pm 11$ & $49 \pm 9$ \\
\hline Color & $20 \pm 6$ & $19 \pm 6$ \\
\hline Skin tone & $20 \pm 5$ & $41 \pm 7$ \\
\hline Stain & $54 \pm 11$ & $55 \pm 13$ \\
\hline
\end{tabular}

\section{Effect of DHG on Tyrosinase Activity}

The DHG-treated B16-F10 cells under $100 \mathrm{~mJ}$ of UVB exposure were compared for tyrosinase activity. The results showed that both extracts of DHG (at $1 \mathrm{mg} / \mathrm{ml}$ ) inhibited tyrosinase activities of 10.7 to $14.1 \%$ as compared to that of the UVB group (Figure 2).

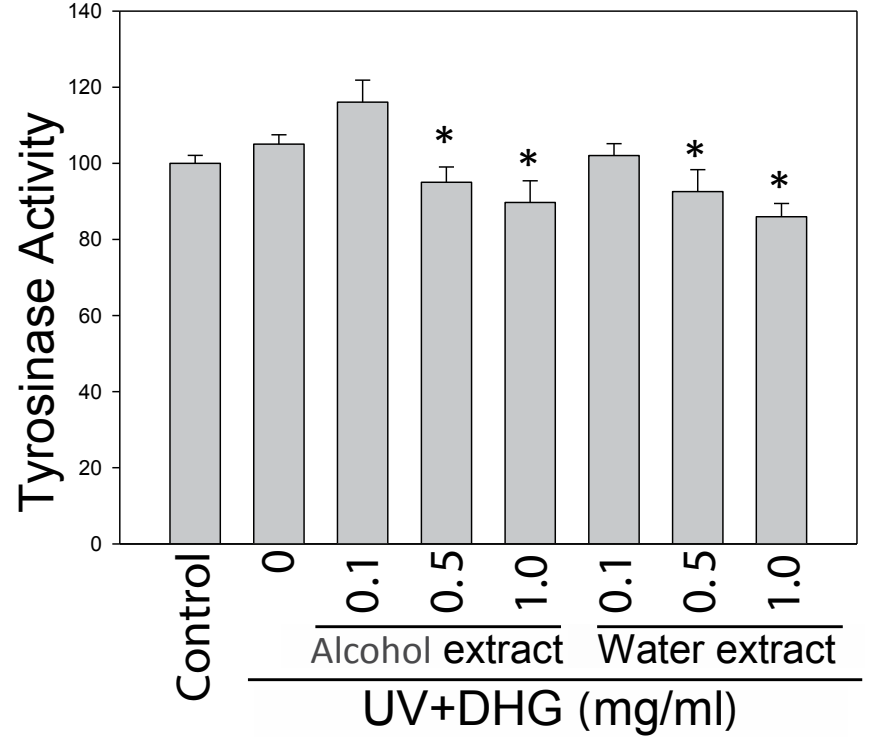

Figure 2: Inhibition of tyrosinase activity by DHG treatment. Tyrosinase activity of B16-F10 cells was compared for the treatment with and without DHG for $48 \mathrm{~h}$. Each value is the mean \pm SE from three experiments. ${ }^{*} p<0.05$ as compared with the UVB-treated control of B16-F10 cells.

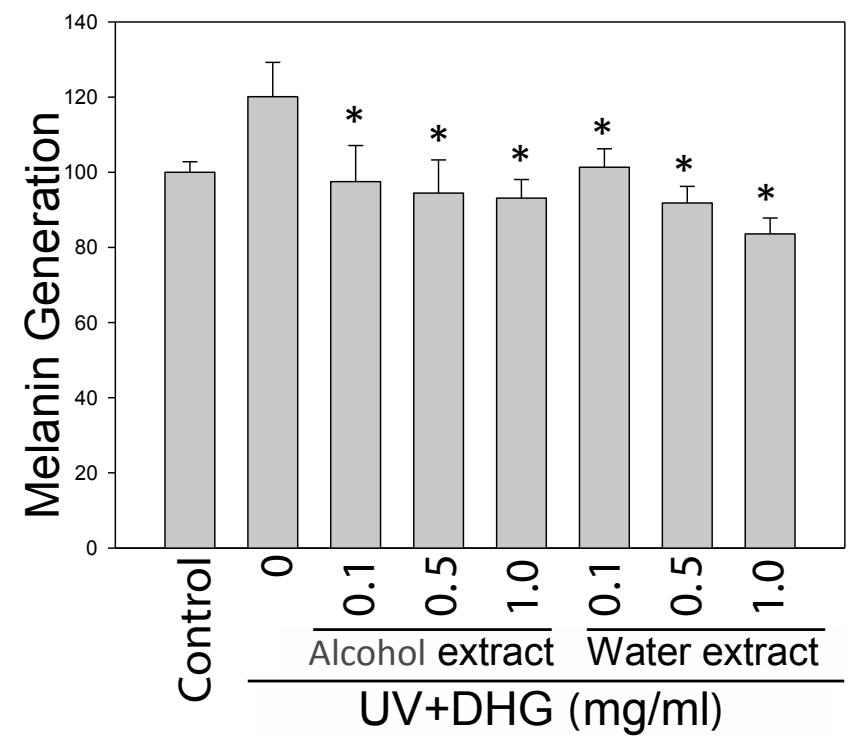

Figure 3: Inhibition of the melanin generation by DHG treatment. The melanin content of B16-F10 cells was assessed for $24 \mathrm{~h}$ treatment with and without DHG. Each value is the mean \pm SE from three experiments. ${ }^{*} p<0.05$ as compared with the UVB-treated control.

\section{Effect of DHG on Melanin Content of B16-F10 Cells}

To further evaluate the potential of DHG as an anti-melanogenic agent, the melanin content from DHG-treated B16-F10 cells under $100 \mathrm{~mJ}$ of UVB exposure was determined. At $24 \mathrm{~h}$ post-treatment, the melanin content measured an absorbance at $405 \mathrm{~nm}$. The result showed that water extract of DHG $(1 \mathrm{mg} / \mathrm{ml})$ had a melanin inhibitory activity of $16.4 \%$ (Figure 3).

\section{Effect of DHG on ROS Generation}

Since DHG had a skin care effect on texture, pores, and wrinkles, it was necessary to examine its effect on the cells under oxidative stress. Therefore HaCaT cells pretreated with $10 \mu \mathrm{M} \mathrm{H}_{2}$ DCF-DA and DHG 
were under $\mathrm{H}_{2} \mathrm{O}_{2}$ stress for 60 or $120 \mathrm{~min}$. Cellular fluorescence was monitored for ROS generation. As we expected, the result showed that ROS was dose-dependently reduced by treatments of water extract of DHG (from 0.5 to $1 \mathrm{mg} / \mathrm{ml}$ ) (Figure 4 ).

\section{Effect of DHG on Cell Signaling Pathways}

The cells were treated with various concentration of DHG for $1 \mathrm{~h}$ at $37^{\circ} \mathrm{C}$, but B16-F10 cells were treated under UVB $(100 \mathrm{~mJ})$ stress. The results showed that DHG enhanced the phosphorylation of ERK significantly, but moderately on JNK, ERK, and p38 proteins in $\mathrm{HaCaT}$ cells. Interestingly, DHG dose-dependently enhanced phosphorylation of ERK, but reduced p-JNK and p-p38 proteins in B16-F10 cells under the UV stress (Figure 5).

\section{Discussion}

The results show that DHG has no cytotoxic effect on the cell viability of HaCaT keratinocytes and B16-F10 melanoma cells. This is consistent with the use donkey hide in traditional Chinese medicine, which has been used for over 2,000 years for its unique therapies. The results showed that DHG has an anti-melanogenic effect by inhibiting tyrosinase activity and reducing melanin contents in B16-F10 melanocytes. These results suggest that DHG from donkey hide can be a potential candidate for development as an anti-pigmenting agent. Interestingly, DHG dose-dependently enhanced the proliferation of HaCaT keratinocytes and B16-F10 melanocytes. It has been reported that keratinocytes from the epidermis participates wound repair in the skin $[14,15]$. Keratinocytes contribute to melanocyte activity by influencing their microenvironment, partly through the secretion of endothelin-1 proteins [16]. In addition, DHG reduced $\mathrm{H}_{2} \mathrm{O}_{2}$-induced ROS generation significantly. Since there is a close relationship between oxidative stress and ageing [17], these results suggest that DHG together with other compounds $[12,18,19]$, might help to preserve a healthy epidermis and dermis and prevent the visible signs of skin aging. This was also demonstrated by a short-term treatment

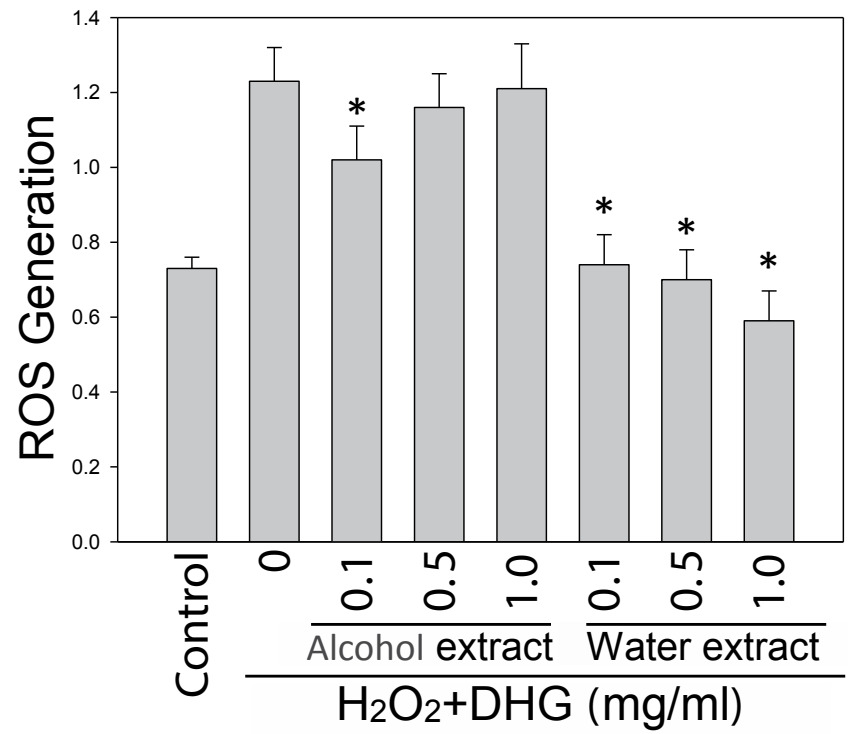

Figure 4: Effect of DHG on ROS generation. HaCaT cells pretreated with $\mathrm{H}_{2} \mathrm{DCF}-\mathrm{DA}$ and DHG were exposed to $\mathrm{H}_{2} \mathrm{O}_{2}$ for $60 \mathrm{~min}$. Each ROS value is the mean $\pm \mathrm{SE}$ from three experiments. ${ }^{*} p<0.05$ as compared with the $\mathrm{H}_{2} \mathrm{O}_{2}$-treated control.
(A)
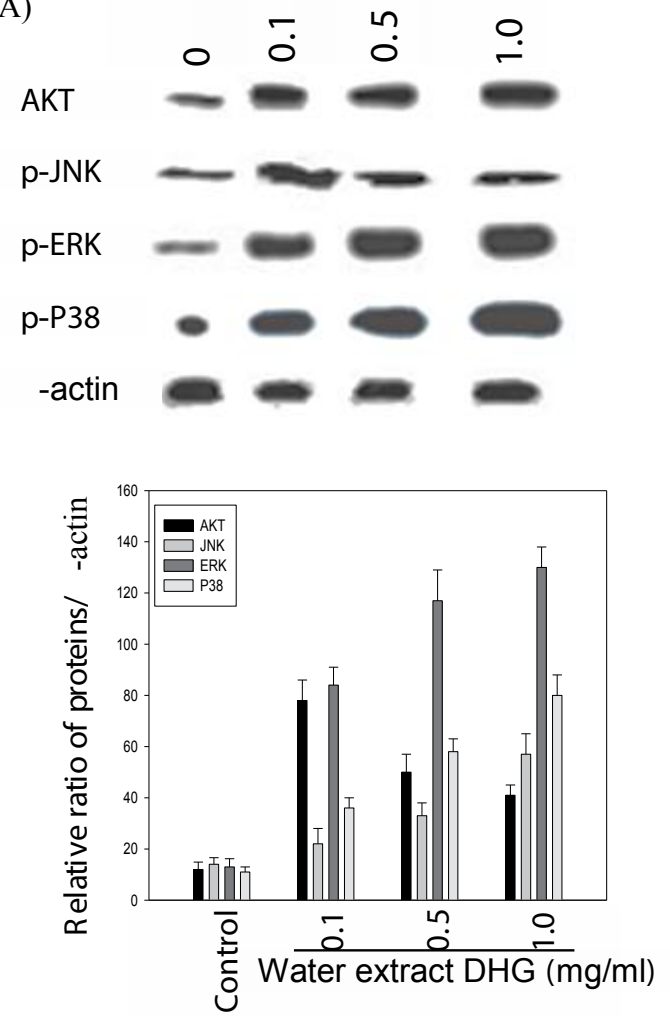

(B)
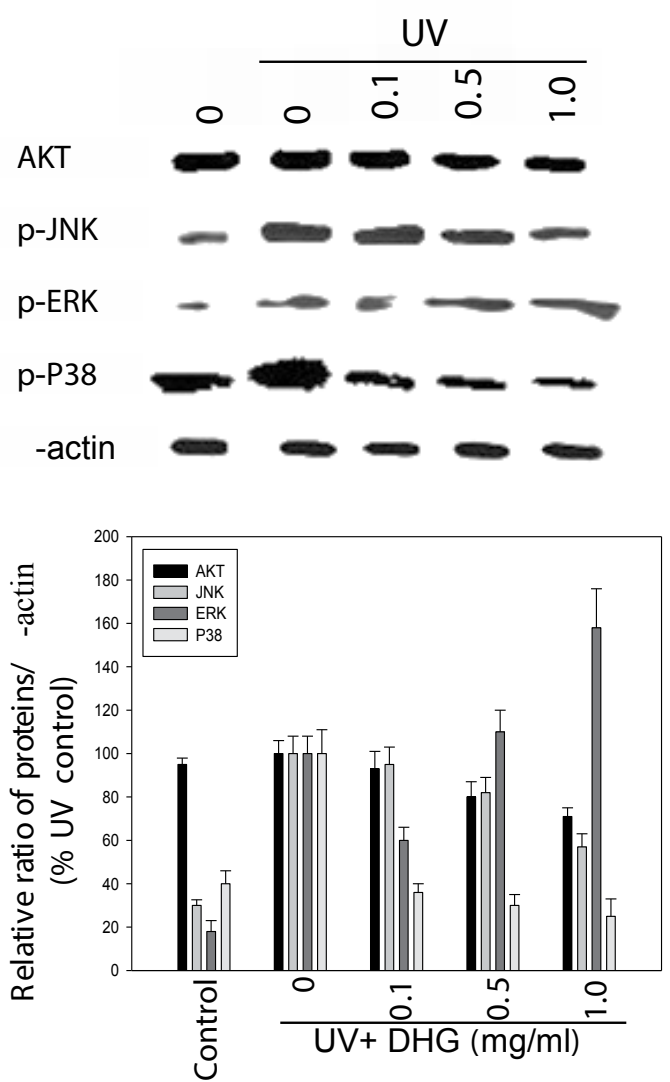

Figure 5: Effect of DHG on cell signaling pathways. HaCaT cells were treated DHG and B16-F10 cells were treated with DHG and under UVB $(100 \mathrm{~mJ})$ stress for $1 \mathrm{~h}$ at $37^{\circ} \mathrm{C}$. Representative data of AKT, phosphorylation of JNK, ERK, and $\mathrm{p} 38$ proteins are shown in $\mathrm{HaCaT}$ cells (A) and B16-F10 cells (B). 
of DHG on healthy volunteers' facial skin textures, pores, wrinkles, and red spots.

One of the key amino acids of Colla corii asini is glycine [20]. Two human major collagen peptides, prolyl-hydroxyproline (ProHyp) and hydroxyprolyl-glycine (Hyp-Gly enhance cell proliferation. In addition, Pro-Hyp enhances the production of hyaluronic acid by dermal fibroblasts [16]. Glycine functions as a building block in the production of proteins. Glycine is a non-essential amino acid, which means it can be synthesized within the human body, therefore cosmetics and skin care products, glycine primarily functions as an anti-ageing ingredient based on its ability to improve moisture retention, increase collagen production, and promote skin repair and regeneration. Other bioactive compounds from Colla corii asini may also contribute its anti-aging, antitumor, immunomodulatory, anti-inflammatory and anti-anemic effects $[21,22]$.

Melanogenesis in melanocytes is regulated by a very complex system [6]. ERK and PI3K/Akt signaling pathways have been shown to negatively regulate melanogenesis in melanocytes and melanoma cells $[3,23]$. Our results show that DHG dose-dependently enhanced phosphorylation of ERK, but reduced p-JNK and p-p38 proteins in B16-F10 cells under the UV stress. This is in agreement with a report that ceramide inhibits melanogenesis by activation of ERK and inhibition of ERK and Akt causes an increase in pigmentation in human melanocytes [12]. Similarly, imidazole derivative and thaginin A can inhibit tyrosinase and activate the ERK pathway [19,24-26].

\section{Conclusion}

In summary, DHG was not cytotoxic to cells and had an anti-melanogenic effect by inhibiting tyrosinase activity and reducing melanin contents in B16-F10 melanocytes. It also showed an antioxidative effect of reducing ROS generation in $\mathrm{H}_{2} \mathrm{O}_{2}-$ stressed HaCaT keratinocytes. DHG dose-dependently enhanced phosphorylation of ERK, but reduced p-JNK and p-p38 proteins in B16-F10 cells under the UV stress. These beneficial mechanisms suggest its potential application in skin care.

\section{Acknowledgement}

The authors wish to thank the Testing and Analysis Center at Yuanpei University of Medical Technology (Hsinchu, Taiwan) for the HPLC analysis.

\section{References}

1. Ando H, Kondoh H, Ichihashi M, Hearing VJ (2007) Approaches to identify inhibitors of melanin biosynthesis via the quality control of tyrosinase. Journal Investigative Dermatology 127: 751-761. [crossref]

2. Birch-Machin MA, Bowman A (2016) Oxidative stress and ageing. British Journal of Dermatology 2: 26-29. [crossref]

3. Chan CF, Lai ST, Guo YC, Chen MJ (2014) Inhibitory effects of novel synthetic methimazole derivatives on mushroom tyrosinaseand melanogenesis. Bioorganic \& Medicinal Chemistry 22: 2809-2815.

4. Chang TS (2009) An updated review of tyrosinase inhibitors. International Journal of Molecular Science 10: 2440-2475. [crossref]

5. Claudinot S, Nicolas M, Oshima H, Rochat A, Barrandon Y (2005) Long-term renewal of hair follicles from clonogenic multipotent stem cells. Proceedings of the National Academy of Sciences of the United States of America 102: 14677-14682.
6. Costin GE, Hearing VJ (2007) Human skin pigmentation: melanocytes modulate skin color in response to stress. The FASEB J 21: 976-994. [crossref]

7. Dorni AC, Amalraj A, Gopi S, Varma K, Anjana SN (2017) Novel cosmeceuticals from plants - an industry guided review. Journal of Applied Research on Medicinal and Aromatic Plants 7: 1-26.

8. Hameury S, Borderie L, Monneuse JM, Skorski G, Pradines D (2019) Prediction of skin anti-aging clinical benefits of an association of ingredients from marine and maritime origins: Ex vivo evaluation using a label-free quantitative proteomic and customized data processing approach. Journal of Cosmetic Dermatology 18: 355-370. [crossref]

9. Hou CW, Chen YL, Chuang SH, Wang JS, Jeng KC (2014) Protective effect of a sesamin derivative, 3-bis (3-methoxybenzyl) butane-1, 4-diol on ischemic and hypoxic neuronal injury. Journal of Biomedical Science 21: 15. [crossref]

10. Huang CC, Hsu BY, Wu NL, Tsui WH, Lin TJ, et al. (2010) Anti-photoaging effects of soy isoflavone extract (aglycone and acetylglucoside form) from soybean cake. International Journal of Molecular Science 11: 4782-4795. [crossref]

11. Kim DS, Kim SY, Chung JH, Kim KH, Eun HC, et al. (2002) Delayed ERK activation by ceramide reduces melanin synthesis in human melanocytes. Cellular Signalling 14: 779-785. [crossref]

12. Peng LH, Liu S, Xu SY, Chen L, Shan YH, et al. (2013) Inhibitory effects of salidroside and paeonol on tyrosinase activity and melaninsynthesis in mouse B16F10 melanoma cells and ultraviolet B-induced pigmentation in guinea pig skin. Phytomedicine 20: 1082-1087. [crossref]

13. Huang JH, Huang CC, Fang JY, Yang C, Chan CM, et al. (2010) Protective effects of myricetin against ultraviolet-B-induced damage in human keratinocytes. Toxicology In Vitro 24: 21-28. [crossref]

14. Hyter S, Coleman DJ, Ganguli-Indra G, Merrill GF, Ma S, et al. (2013) Endothelin-1 is a transcriptional target of $\mathrm{p} 53$ in epidermal keratinocytes and regulates ultravioletinduced melanocyte homeostasis. Pigment Cell \& Melanoma Research 26: 247-258. [crossref]

15. Inoue N, Sugihara F, Wang $X$ (2016) Ingestion of bioactive collagen hydrolysates enhance facial skin moisture and elasticity and reduce facial ageing signs in a randomised double-blind placebo-controlled clinical study. Journal of the Science of Food and Agriculture 96: 4077-4081. [crossref]

16. Ito M, Liu Y, Yang Z, Nguyen J, Liang F, et al. (2005) Stem cells in the hair follicle bulge contribute to wound repair but not to homeostasis of the epidermis. Nature Medicine 11: 1351-1354. [crossref]

17. Kim DS, Lee HK, Park SH, Chae CH, Park KC (2009) AVS-1357 inhibits melanogenesis via prolonged ERK activation. Die Pharmazie 64: 532-537. [crossref]

18. Wang D, Ru W, Xu Y, Zhang J, He X, et al. (2014) Chemical constituents and bioactivities of Colla corii asini. Drug Discoveries \& Therapeutics 8: 201-207. [crossref]

19. Shen L, Chen H, Zhu Q, Wang Y, Wang S, et al. (2016) Identification of bioactive ingredients with immuno-enhancement and anti-oxidative effects from FufangEjiao-Syrup by LC-MS(n) combined with bioassays. Journal of Pharmaceutical and Biomedical Analysis 117: 363-371. [crossref]

20. Wu H, Ren C, Yang F, et al. (2016) Extraction and identification of collagenderived peptides with hematopoietic activity from Colla Corii Asini. Journal of Ethnopharmacology 182: 129-136.

21. Oka M, Nagai H, Ando H, et al. (2000) Regulation of melanogenesis through phosphatidylinositol 3-kinase-Akt pathway in human G361 melanoma cells. Journal of Investigative Dermatology 115: 699-703.

22. Kim JH, Baek SH, Kim DH, Choi TY, Yoon TJ, et al. (2008) Downregulation of melanin synthesis by haginin A and its application to in vivo lightening model. Journal of Investigative Dermatology 128: 1227-1235.

23. Lee SY, Baek N, Nam T-g (2016) Natural, semisynthetic and synthetic tyrosinase inhibitors. Journal Enzyme Inhibition and Medicinal Chemistry 31: 1-13. [crossref]

24. Lv P, Zhao YJ, Qi F, Zhou XS, You JH, et al. (2011) Authentication of equine DNA from highly processed donkey-hide glue (Colla corii asini) using sine element. Journal of Food and Drug Analysis 19: 123-130. 
Chien Wei Hou (2021) Mechanisms of Anti-Melanogenic and Proliferative Effects of Colla Corii Asini (E'jiao)

25. Wang D, Liu M, Cao J, Cheng Y, Zhuo C, et al. (2012) Effect of Colla corii asini (E'jiao) on D-galactose induced aging mice. Biological and Pharmaceutical Bulletin 35: 2128-2132. [crossref]
26. Wu HZ, Yang F, Cui SY, Qin YF, Liu JW, et al. (2007) Hematopoietic effect of fractions from the enzyme digested colla corii asini on mice with 5-fluorouracil induced anemia. The American Journal of Chinese Medicine 35: 853-866. [crossref]

\section{Citation:}

Hou CW (2021) Mechanisms of Anti-Melanogenic and Proliferative Effects of Colla Corii Asini (E'jiao). Internal Med Res Open J Volume 6(2): 1-6. 